\title{
METAGRANITÓIDES DO COMPLEXO CAICÓ, NE DO BRASIL: ASPECTOS GEOQUÍMICOS DE UM MAGMATISMO CÁLCICO-ALCALINO NA TRANSIÇÃO ARQUEANO - PALEOPROTEROZÓICO
}

\author{
Z.S.Souza ${ }^{1,2}$, E.F.Jardim de Sá ${ }^{1,2,3}$, H.Martin ${ }^{4}$
}

O Complexo Caicó (CC) corresponde aos terrenos de alto grau que servem de embasamento ao Grupo Seridó na Província Borborema, NE do Brasil (Jardim de Sá, 1994). 0 CC compreende seqüências vulcanossedimentares intrudidas por metaplutônicas diversas. Estas últimas englobam: (i) rochas básicas a intermediárias $(R B I)$, variando de gabros/dioritos a melatonalitos; (ii) gnaisses finos, cinza a róseos, tonalíticos (TON) a graníticos (GR); (iii) augen gnaisses $(A G)$ granodioríticos a graníticos, intrusivos nos dois primeiros (Souza, 1991; Souza et al., 1993). Datações $\mathrm{U} / \mathrm{Pb}$ e $\mathrm{Pb} / \mathrm{Pb}$ (evaporação) em zircões e isócronas $\mathrm{Rb} / \mathrm{Sr}$ de ortognaisses e metagabros nas áreas de São Vicente/Florânia, Caicó e Açu, apresentaram idades na faixa de 2,23-2,15 Ga e baixos valores da razão inicial de $\mathrm{Sr}(0,7023-0,7028)$ (Hackspacher et al., 1990; Souza et al., 1993). Os metagabros forneceram idades modelo de $\mathrm{Nd}\left(\mathrm{T}_{\mathrm{TDM}}\right)$ de 2,65-2,62 Ga, com $\mathrm{e}_{\mathrm{Nd}}$ de $-2,5$ a $-2,8$ (Hackspacher et al., 1990). 0 presente artigo discute a geoquímica das metaplutônicas do CC, tema em parte já abordado por Souza (1991), Dantas (1992) e Souza et al. (1993), comparando-as a granitóides juvenis de idades Arqueana e moderna (Martin, 1986, 1994).

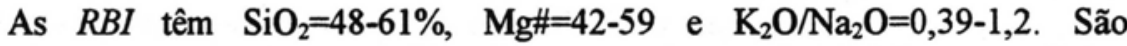
subsaturadas a ligeiramente saturadas em sílica $(\mathrm{Qz}$ normativo $=0,4-15 \%)$, com olivina normativa em algumas amostras. $\mathrm{O}$ comportamento compativel de $\mathrm{Co}, \mathrm{V}$ e $\mathrm{Sr}$, e incompativel de $\mathrm{Rb}, \mathrm{Ba}, \mathrm{Y}$ e $\mathrm{Zr}$, aliado aos padrões de elementos maiores sugerem um cumulado com predomínio de anfibólio (Anf), diopsídio (Dio), plagioclásio (Pl) e biotita (Bt). $\mathrm{SiO}_{2}$ de $T O N$ e $G R$ varia de 63 a 77\%, sendo de 57-76\% em $A G$. Mg\#=31-47 em TON, 22-45 em $A G$ e 15-47 em GR. As razões $\mathrm{K}_{2} \mathrm{O} / \mathrm{Na}_{2} \mathrm{O}$ são menores em $\operatorname{TON}(0,25-1,2)$ do que em $G R$ e $A G(0,52-2,52)$. Todas essas rochas são saturadas em sílica, com Qz normativo entre 12 e 39\%. Os Anf de TON e $A G$ são cálcicos, correspondendo $\mathrm{Mg}$-hornblendas hastingsíticas e hornblendas Fe-edeníticas (Leake, 1978), sendo

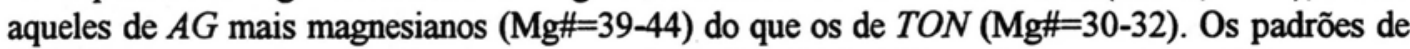
óxidos maiores e relações elementos compatíveis $(\mathrm{Co}, \mathrm{V}, \mathrm{Sr}, \mathrm{Y})$ vs. incompativeis $(\mathrm{Rb})$ sugerem uma evolução por taxas variadas (37-65\%) de cristalização fracionada (cf) de diferentes proporções de $\mathrm{Pl}$, Anf, Bt, titanita (Tit) e magnetita (Mgt). Os ortognaisses do CC são normalmente enriquecidos nos ETRL, com razões $(\mathrm{La} / \mathrm{Yb})_{\mathrm{N}}$ médias de 11,2 (RBI), 12,9 (TON), 33,1 (AG) e 21,4 (GR), e Yb $\mathrm{N}_{\mathrm{N}}$ médio de 11,4 (RBI), 9,4 (GR) e 9,7 (TON).

As metaplutônicas do CC seguem trends intermediários entre cálcico-alcalino e shoshonítico em diagramas $\mathrm{R}_{1}-\mathrm{R}_{2}$ e Q-P. No triângulo catiônico K-Na-Ca e no gráfico $\mathrm{K}_{2} \mathrm{O}$ vs.

\footnotetext{
Apoio FINEP/PADCT e CAPES/COFECUB.

'Departamento de Geologia, Universidade Federal do Rio Grande do Norte.

${ }^{2}$ Núcleo de Pesquisa em Geodinâmica e Geofísica, Universidade Federal do Rio Grande do Norte.

${ }^{3}$ Pesquisador do CNPq.

${ }^{4}$ Université Blaise Pascal/CNRS.
} 
$\mathrm{SiO}_{2}$, definem uma afinidade cálcico-alcalina potássica. Diversas características geoquímicas dessas rochas são comparáveis àquelas dos granitóides tipos $\mathbf{M}$ ou $\mathrm{I}$, sem ou com restritas evidências de componentes crustais na sua gênese, destacando-se: (i) baixas razões isotópicas iniciais do $\mathrm{Sr}$; (ii) variação desde termos básicos a intermediários e ácidos, em cada suíte; (iii) presença de Anf, Mgt e Dio; (iv) ausência de aluminossilicatos, com coríndom normativo < $1,0 \%$; (v) caráter essencialmente metaluminoso dos magmas, com $\mathrm{A} / \mathrm{CNK}<1,1$ e $\mathrm{A} / \mathrm{NK}>1,0$.

Diagramas discriminantes utilizando $\mathrm{Rb}, \mathrm{Y}$ e $\mathrm{Nb}$ sugerem um ambiente de arco magmático, tendo parte dos $A G$ e $G R$ afinidades com séries shoshoníticas (Jardim de Sá, 1994). TON mostram teores de $\mathrm{Ta}$ e $\mathrm{Nb}$ comparáveis aos de granitóides de arco oceânico, enquanto $\mathrm{Hf}, \mathrm{Zr}$, Sm e Y são afins aos de margem continental ativa. Admite-se, deste modo, um contexto de subducção para os granitóides do CC. Em zonas de subducção, magmas cálcicoalcalinos podem ter como fonte a crosta oceânica ou a cunha do manto. A gênese desses magmas depende de interações complexas entre o gradiente geotérmico e o grau de desidratação da crosta oceânica (síntese em Martin, 1986). No Arqueano, a fusão parcial ( $f p$ ) dessa crosta dá-se quando ela ainda é quente e hidratada, gerando liquidos tonaliticos. Atualmente esta crosta está fria e desidrata antes de ser fundida, liberando fluidos que enriquecem a cunha do manto sobrejacente em elementos incompativeis e provocam a sua fusão parcial, deixando um resíduo harzburgítico. As caracteristicas dos ortognaisses do $\mathrm{CC}$ sugerem uma fonte mantélica metassomatizada (explicando, assim, os valores negativos de $\varepsilon_{\mathrm{Nd}}$ em rochas juvenis) com pouca granada no resíduo. Cálculos geoquímicos considerando as amostras menos evoluídas de $R B I, T O N, G R$ e $A G$ indicam que: (i) no caso das $R B I$, a gênese seria feita a partir de $15-20 \%$ de $f p$ de lherzolito com $<2 \%$ de Gra, ou $30-40 \%$ de fusão parcial de lherzolito com $10 \%$ de Gra, neste caso seguido por $60-70 \%$ de $c f$ de olivina (Ol); (ii) para $T O N$ e $A G$, a gênese se daria a partir de $10-25 \%$ de $f p$ de fontes lherzolíticas variavelmente metassomatizadas, contendo pequena quantidade (1-2\%) de $\mathrm{Gra}$, formando magmas parentais básicos a intermediários, que evoluiriam a seguir com diferentes taxas de $c f$ de $\mathrm{Ol}$ em níveis subcrustais.

0 Arqueano $(>2,5 \mathrm{Ga})$ corresponde a um periodo com predomínio de alto gradiente geotérmico, vigorosa convecção e volumoso plutonismo trondhjemítico-tonalíticogranodiorítico (TTG) derivado de fusão parcial de crosta oceânica. O Proterozóico marca a passagem a um regime de gradientes comparativamente menores ou diversificados, com geração de magma a partir da cunha do manto acima de zonas de subducção (Martin, 1986, 1994). Os TTGs (Martin, 1994) têm Bt como mineral máfico mais importante e seguem o trend de enriquecimento em $\mathrm{Na}_{2} \mathrm{O}$. A Tabela 1 mostra algumas razões elementares médias de TTGs arqueanos e de granitóides modernos em contexto de subducção. Os ortognaisses do CC são comparáveis aos granitóides modernos, notadamente pelos seus maiores valores de $\mathrm{K}_{2} \mathrm{O} / \mathrm{Na}_{2} \mathrm{O}$, $\mathrm{Fe}_{2} \mathrm{O}_{3} \mathrm{t}, \mathrm{Yb}_{\mathrm{N}}, \mathrm{Rb} / \mathrm{Sr}$, Th/U e Sc/Hf, e menor $\mathrm{Mg} \#$. $\mathrm{Yb}_{\mathrm{N}}, \mathrm{Th} / \mathrm{U}$ e Sc/Hf têm valores parcialmente superpostos aos de TTGs arqueanos. Portanto, pode-se admitir que os mecanismos de geração e evolução de magmas no $\mathrm{CC}$ seriam semelhantes àqueles de contextos modernos de subducção.

$\mathrm{O}$ plutonismo paleoproterozóico do CC distingue-se dos TTGs arqueanos por não seguir o trend de diferenciação trondhjemítico, por seus valores maiores de $\mathrm{Yb}_{\mathrm{N}}, \mathrm{K}_{2} \mathrm{O} / \mathrm{Na}_{2} \mathrm{O}$ e

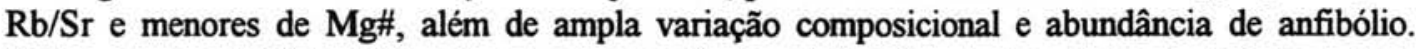
Assim como os TTGs, interpreta-se um ambiente de subducção, porém a fonte de magma seria a cunha do manto metassomatizado, e não a crosta oceânica. Nestes termos, os ortognaisses do CC representam um magmatismo juvenil gerado em contexto de subducção, provavelmente em sucessivos episódios de acresção de arcos magmáticos no período 2,3-2,15 Ga (Jardim de Sá, 1994). Permanece em aberto o papel exercido pelo material supracrustal (metavulcânicas e metassedimentos) do próprio $\mathrm{CC}$, já que não se encontraram vestígios geoquímicos dos mesmos nos ortognaisses. Uma possibilidade é a de que eles tenham contribuido apenas com fluidos superaquecidos liberados pela desidratação durante a subducção. Por outro lado, metabasaltos/ 
andesitos do $\mathrm{CC}$ possuem composições químicas afins àquelas dos granitóides, confirmando o modelo genético proposto para o plutonismo.

Tabela 1 - Comparação geoquímica dos ortognaisses do Complexo Caicó/RN com respeito aos TTGs arqueanos e granitóides modernos (Martin, 1994).

\begin{tabular}{|c|c|c|c|}
\hline & $\begin{array}{l}\text { GRANITÓIDES } \\
\text { ARQUEANOS }\end{array}$ & $\begin{array}{l}\text { GRANITÓIDES } \\
\text { MODERNOS }\end{array}$ & $\begin{array}{c}\text { COMPLEXO } \\
\text { CAICÓ }\end{array}$ \\
\hline $\mathrm{K}_{2} \mathrm{O} / \mathrm{Na}_{2} \mathrm{O}$ & 0,36 & 0,92 & $0,66-1,42$ \\
\hline $\mathrm{Fe}_{2} \mathrm{O}_{3} \mathrm{t} / \mathrm{MgO}$ & 2,64 & 2,81 & $2,8-4,4$ \\
\hline Mg\# & 43 & 41 & $30-39$ \\
\hline $\mathrm{Yb}_{\mathrm{N}}$ & $0,3-8,5$ & $4,5-20$ & $9,7-11,4$ \\
\hline $\mathrm{Rb} / \mathrm{Sr}$ & 0,12 & 0,35 & $0,14-1,7$ \\
\hline $\mathrm{Th} / \mathrm{U}$ & 4,31 & 3,93 & $3,42-6,486$ \\
\hline $\mathrm{Sc} / \mathrm{Hf}$ & 1,04 & 2,83 & $0,81-4,56$ \\
\hline FONTE & $\begin{array}{l}\text { granada anfibolito, } \\
\text { hornblenda eclogito }\end{array}$ & $\begin{array}{l}\text { cunha mantélica } \\
\text { metassomatizada }\end{array}$ & $?$ \\
\hline $\begin{array}{l}\text { COMPOSIÇÃO } \\
\text { DO MAGMA }\end{array}$ & $\begin{array}{c}\text { tonalito - trondhjemito - } \\
\text { granodiorito }\end{array}$ & $\begin{array}{l}\text { basalto - andesito - } \\
\text { dacito - riolito }\end{array}$ & $\begin{array}{c}\text { gabro - tonalito - } \\
\text { granodiorito - granito }\end{array}$ \\
\hline
\end{tabular}

\section{Referências Bibliográficas}

DANTAS, E.L. (1992) Evolução tectono-magmática do maciço polidiapirico São Vicente/Floriana-RN. Rio Claro, 272p. (Dissertação - Mestrado) - Instituto de Geociências, Universidade Estadual Paulista.

HACKSPACHER, P.C.; VAN SCHUMS, W.R.; DANTAS, E.L. (1990) Um embasamento transamazônico na província Borborema. In: CONGRESSO BRASILEIRO DE GEOLOGIA, 36., Natal, 1990. Anais. Natal, SBG-NE. v.6, p.2683-2696.

JARDIM DE SÁ, E.F. (1994) A faixa Seridó (Província Borborema, NE do Brasil) e seu significado geodinâmico na cadeia brasiliana/pan-africana. Brasília, 804p. (Tese Doutorado) - Instituto de Geociências, Universidade de Brasilia.

LEAKE, B.E. (1978) Nomenclature of amphiboles. American Mineralogist, v.63, n.11-12, p.1023-1052.

MARTIN, H. (1986) Effect PF steeper archean geothermal gradient on geochemistry of subduction-zone magmas. Geology, v.14, n.9, p.753-756.

MARTIN, H. (1994) The archean grey gneisses and the genesis of continental crust. In: CONDIE, K.C. (Ed.) Archean crustal evolution. Amsterdam, Elsevier, p.205-259. (Developments in precambrian geology, 11)

SOUZA, Z.S. (1991) Mèmoir de DES. Université de Rennes.

SOUZA, Z.S.; MARTIN, H.; MACEDO, M.N.F.; PEUCAT, J.J.; JARDIM DE SÁ, E.F. (1993) Un segment de croûte continentale juvénile d'âge protérozoique inférieur: le complexe de Caicó (Rio Grande do Norte, NE-Brésil) Comptes Rendus Academie des Sciences Paris. Série II, t.316, p.201-208. 